\title{
An Experimental Examination of Electoral Expectations
}

\author{
Russell K. Mayer
}

Research on so-called bandwagon effects convincingly has established that individuals distinctly prefer expected winners to expected losers when they evaluate candidates for office. This article examines variation in the framing of electoral expectations which produce bandwagon effects, and the ways in which this variation matters. In particular, it considers how the media's affective (positive/negative) and attributional (personal/situational) framing of expectations influences people's propensity to support an expected winner. The experimental results presented suggest that variations in electoral expectations lead to systematic differences in the magnitude of bandwagon effects, the negative-personal frame exerting the largest influence on vote choice.

The growing body of research on electoral expectations has produced two primary findings: (1) expectations information abounds in the media; and (2) this information affects vote choice. The media's tendency to report on the "horserace" rather than more substantive aspects of election contests has been well documented (Brady and Johnston 1987; Just et al. 1996; Morin 1995; Patterson 1980). This proliferation of information on who's ahead and who's behind is sobering for those interested in promoting reasoned campaign discourse focused on matters of public policy. Furthermore, the media's provision of so much expectations information has led researchers to examine what effect expectations have on voters' electoral choices. A variety of experimental and survey-based methodologies have demonstrated a net positive bandwagon effect: expected electoral success correlates positively with levels of candidate support (Bartels 1985; Kenney and Rice 1994; Lavrakas et al. 1991; McKelvey and Ordeshook 1985; Mehrabian 1998; Mutz 1997; Traugott 1992).

For the most part, researchers studying electoral expectations have treated all expectations information alike. In documenting the prevalence of media expectations, they have not attempted to distinguish among different kinds of expectations information, and they have paid little attention to how variations in expectations information might create more or less powerful bandwagon effects. In a recent analysis of campaign coverage, I show that media presentations of expectations information do in fact vary substantially (Mayer 2001). Beyond conveying the basic idea that a particular candidate is likely to win a given election, the media provide a range of different

Russell K. Mayer is Assistant Professor of Political Science at Merrimack College.

The American Review of Politics, Vol. 23, Spring, 2002: 39-54

(C)2002 The American Review of Politics 
reasons for or explanations of those expectations, including campaign tactics, group support, and economic conditions.

Given that expectations information varies, this article addresses the question of whether different types of expectations information affect candidate support and vote choice. I begin by laying out two frames for electoral expectations that should be particularly powerful in inducing bandwagon effects: an affective frame and an attributional frame. Drawing on experimental data, I examine the impact of these two different ways of framing expectations on the magnitude of electoral bandwagons. Finally, in the conclusion, I discuss the implications for how expectations information affects the electoral process.

\section{Affective and Attributional Frames in Expectations Information}

The basic argument of framing theory is that opinions are influenced not just by the substantive content of the information communicated (i.e., the message), but also by the presentation of that information. Frames emphasize particular aspects of complex phenomena about which individuals possess multiple considerations (Zaller 1990). They lead individuals to accept certain interpretations and evaluations of these objects and to reject others, shaping opinions in the process. Framing has proven extremely useful in understanding the effects of political communication, particularly mediated communication, on citizen attitudes. It has been shown to affect public opinion on race (Gross 2000; Kinder and Sanders 1990), abortion policy (Freedman 1996), and political tolerance (Nelson et al. 1997). Given its value in linking media messages and public opinion in other contexts, framing theory offers a compelling conceptual basis from which to examine the relationship between electoral expectations and candidate preferences. In particular, I suggest that the affective and attributional aspects of expectations information are likely to influence citizens' reactions to political candidates.

By the affective frame associated with expectations information, I mean simply whether the expectation is framed positively, i.e., Candidate A is likely to win, or negatively, i.e., Candidate B is likely to lose. Both of these frames convey the same expectation that A is likely to beat B, but they inspire different affective associations with each candidate. In turn, this should lead to different propensities to support or vote for each candidate.

In general, negative information has been shown to play a larger role than positive information in helping us evaluate others (Birnbaum 1972; Fiske 1980). In a program of research on the relationship between information and evaluations, Cacioppo and his colleagues develop a theory of 
impression formation that accounts for this so-called negativity bias. They propose a model of impression formation "in which positive and negative evaluative processes are assumed to result from separable positive and negative motivational substrates respectively" (Ito et al. 1998, 887; see also Cacioppo and Berntson 1994; Cacioppo, Gardner, and Berntson 1997). Because these evaluative dimensions are separable, the effects of negative information can and do, in fact, overwhelm those of positive information, leading to an asymmetry in effects. Empirically, they find that the relationship between negative information and evaluations is much stronger than the corresponding relationship between positive information and evaluations. Similar levels of both negative and positive information have different effects on evaluations, the effects of negative information being larger in general.

Evidence of a negativity bias also is apparent in a growing body of research on the effects of negative advertising in political campaigns (Ansolabehere and Iyengar 1995; Finkel and Geer 1998; Freedman and Goldstein 1999; Kahn and Kenney 1999). While there is considerable disagreement over whether the negative information conveyed in attack advertising has mobilizing or demobilizing effects on the electorate, researchers generally have found negative ads to be more powerful than positive ones. In part, the negative information conveyed in these ads is likely to have a larger effect on citizens than corresponding positive information due to the fact that this information is relatively surprising or unusual. As Kahn and Kenney put it $(1999,878)$, "since the preponderance of information people receive in their daily lives is positive, negative information is more unique, more salient, and more memorable" (see also Hamilton and Zanna 1974; Lau 1982, 1985; McGraw and Steenbergen 1997).

These findings that negative information is more powerful than positive information suggest that negatively framed expectations information should be more powerful than positively framed expectations information in affecting vote choice. In essence, being told which candidate is expected to lose an election should have a larger effect on citizen preferences than being told which candidate is expected to win.

A second dimension of electoral expectations that should influence citizen reactions to candidates is the causal attribution associated with that knowledge. This attributional characteristic of expectations frames draws on the well-established distinction between situational and personal causal explanations (Heider 1958; Kelley 1972; Fiske and Taylor 1991). A candidate's expected success or failure may be framed as due to circumstances beyond his or her control, a situational attribution, or because of his or her own qualities or actions, a personal attribution. For example, a situational 
attribution would explain a candidate's expected success based on his or her party's advantage in voter registration. In contrast, a personal attribution of a candidate's expected success would explain his or her likely victory as arising from the candidate's skill as a debater or fundraiser.

A significant body of research points to the power of personal over situational frames. Ross (1977) labels this basic human tendency to privilege personal attributional explanations and discount situational ones the "fundamental attributional error" although he is hardly alone in identifying this phenomenon (see also Gilbert and Malone 1995; Jones and Harris 1967). At a societal level, this preference for personal rather than situational attributions can be understood as an artifact of a Western cultural ethic that emphasizes the causal power of the individual (Norenzayan and Nisbett 2000; Smith and Bond 1994). At a cognitive level, the fundamental attribution results from observers attending to more salient and accessible personal information rather than from not processing other potentially important, but less conspicuous situational information (Taylor and Fiske 1975). The oneto-one correspondence between actor and action makes person-based attributions easy to perform. Processing explanatory information provided by the situation requires additional effort, so in many circumstances this extra step is neglected. According to Forgas $(1998,319)$, "This may suggest something like a two stage process in attributions: Judges first assume dispositions ... and may only correct for situational pressures subsequently if at all" (see also Jones 1979; Quattrone 1982).

What does this tendency toward the fundamental attribution error suggest about how the attributional framing of electoral expectations should affect vote choice? Since most citizens do not have the time, the motivation, or the political sophistication and experience to move beyond basic attributional judgments, politics is one domain in which one would expect simpler (personal) attributions to dominate more sophisticated (situational) ones. Personal attributions should be more likely to resonate with voters when it comes to understanding electoral expectations, and expectations framed in this easily comprehensible way should be likely to have a larger effect on vote choice. As a result, personally framed expectations information should be more powerful than situationally framed expectations information in affecting vote choice.

Finally, in a context in which offers both affective and attributional interpretations of expectations, these two framing effects ought to interact in a logical and predictable way. Bandwagon effects are expected to be greatest when expectations information is framed negatively. As well, personal attributions are expected to produce a more powerful effect on candidate evaluations. Therefore, when these two combine in a negative-personal 
frame, the propensity to support the expected winner (i.e., bandwagon) should be largest. Conversely, when expectations are framed positively and situationally attributable, one should see small, but still positive, bandwagon effects. Here the basic expectation of electoral success is conveyed despite the use of less powerful frames. Since there is no expectation that either the affective or attributional frame should be more powerful than the other, the prediction for the two mixed cases of negatively-situationally and positivelypersonally framed electoral expectations is that both conditions should produce moderate bandwagon effects. Therefore, the interaction hypothesis simply combines the predicted effects of the affective and attributional framing theories in suggesting that negatively-personally framed expectations information should have the largest effect on vote choice, negatively-situationally and positively-personally framed expectations information should have a moderate effect on vote choice, and positively-situationally framed expectations information should have the smallest effect on vote choice.

\section{Method}

To examine these hypotheses about the affective and attributional nature of expectations information and potential for bandwagon effects, an experiment designed to mirror how news accounts frame electoral expectations was conducted. Subjects were randomly assigned to one of five groups-four treatment groups and a control group. The experimental manipulation followed a $2 \times 2$ design in which the affective (positivenegative) and the attributional (personal-situational) components of expectations information provided to subjects varied across groups (see Table 1).

The subjects for the experiment were 290 student volunteers in introductory and upper level political science courses at a small Catholic college in Massachusetts. Pre-test measures were obtained several weeks prior to the experiment from a survey administered to all students in these classes. Compared to the United States population as a whole, this sample is disproportionately male $(57 \%)$, young (all but 3 participants were below the age of 23 ), and white (96\%). Pre-test measures for religion and hometown were not obtained, but it can be relatively safe to assume that the subjects are disproportionately Catholic and residents of Massachusetts or New Hampshire given the college's fairly homogenous demographic profile. Compared to the nation as whole, they are somewhat more likely to identify as independents (32\%) and to consider themselves moderates (36\%).

The randomization of these 290 participants into five groups proved to be quite effective. For none of the 18 measures of political attitudes and 
Table 1. Affective by Attributional (2 x 2) Experimental Design

\begin{tabular}{lccc}
\hline & & \multicolumn{2}{c}{ Affective Frames } \\
& Personal & Group 1 & Negative \\
Attributional & Situational & Group 2 & Group 3 \\
Frames & Group 4 \\
The control group [Group 5] received no information regarding the expected outcome of the race. \\
\hline
\end{tabular}

behaviors obtained in the pre-test did an ANOVA f-test produce a statistically significant $(p<.05)$ difference across groups. The groups did vary significantly on two of the demographic variables measured, year in school and major field of study. Group 4, the negative-situational condition, contained a disproportionate number of first year students. Moreover, the nineteen political science majors in the subject pool were not evenly distributed among the groups (7, 0, 4, 7, 1 across the five conditions). However, these deviations are not especially worrisome in light of the similarity across groups on all measured political variables (e.g., knowledge, interest, and efficacy).

Subjects in each group were asked to read an account of the 2000 Democratic primary for U.S. Senator in New Jersey contested by Jim Florio and Jon Corzine and then to respond to a variety of questions about the race in a post-test questionnaire. In examining how the framing of expectations influences bandwagon effects, the dependent variable of interest was vote choice. ${ }^{1}$ Feeling thermometer ratings for each candidate also were gathered in the post-test as additional measures of candidate evaluations.

In the experimental cover story, subjects were informed that the researchers were interested in studying elections going on around the country and that they were being provided with a news story downloaded from The New York Times web page on the current Senate race in New Jersey. The account of the race was developed based on information gathered from several internet news sites, and it was edited to present a balanced, if not always factually accurate, view of the candidates. ${ }^{2}$ The experimental stimulus provided to subjects fairly closely followed the format used on The New York Times website; in circulating the stimulus to colleagues and in debriefing the experiment, no one questioned its apparent authenticity.

The stimulus varied across groups only in whether the expected outcome was framed a likely Corzine win (positive frame) or a likely Florio 
loss (negative frame), and whether the cause of the expected victory (or loss) was due to hard work (or a lack thereof) in raising campaign funds (personal frame), or whether it was from fortunate or unfortunate situation $v i s$-à-vis campaign funding (situational frame). The control group received no information about who was expected to win the race. This manipulation, the exact wording of which is provided in the Appendix, essentially alters one sentence in a nine-paragraph article, or less than four percent of the total text presented as part of the stimulus. In general, this was a small and relatively subtle manipulation, and its effects should be interpreted accordingly.

\section{Results}

The analysis presented here shows the effects of expectations frames (affective and attributional) on voting for the expected winner. Overall, a positive bandwagon effect was anticipated for all subjects presented with expectations information. In addition, the magnitude of this bandwagon effect should be larger when expectations are framed as negative information and when they are framed as attributable to personal factors. Table 2 presents the experimental evidence of any expectations effects at the most basic level.

The difference of means test indicates strong support for the basic bandwagon hypothesis. Subjects exposed to any information regarding the likely outcome of the election contest were much more likely to vote for the expected winner. Control group subjects showed weak support for Corzine, but the levels of support for Corzine increased 17 percentage points in the

Table 2. Difference in Voting for Expected Winner by Expectations Information

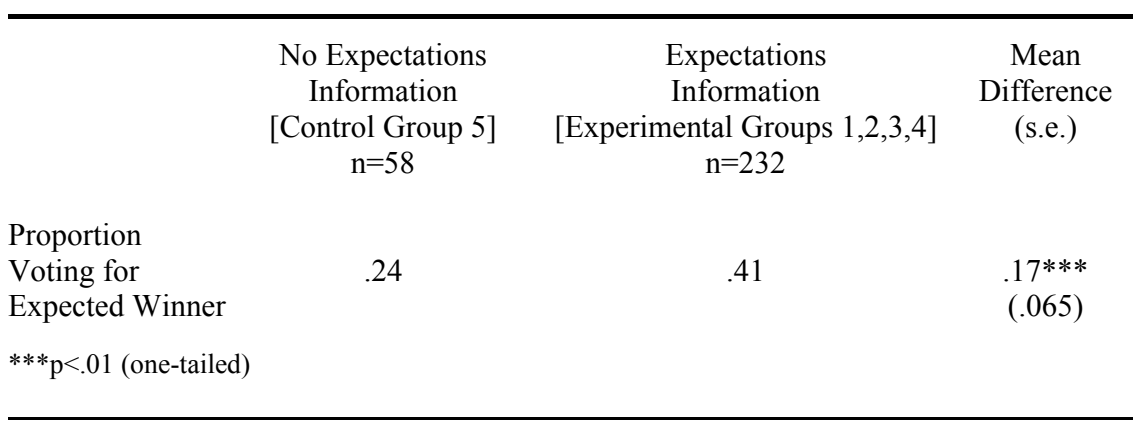


experimental groups where subjects were informed that Corzine was likely to beat Florio. In an electoral context, a difference of this magnitude would not only be likely to alter the interpretation of the race, but it also could very well change its outcome. Table 3 provides evidence on the specific ways in which the affective and attributional framing of exceptions information affects vote choice.

The data in Table 3 appear to support the affective framing hypothesis. Negatively framed expectations information creates a larger bandwagon effect than positively framed expectations ( $21 \mathrm{v} .13 \%)$. Similarly, the data show a pattern of effects consistent with the attributional framing hypothesis. The difference between the control and the situational framing conditions is substantial $(12 \%)$, and statistically significant at $p<.05$, onetailed test. However, the difference between the control and the personal framing conditioning is almost twice as large $(22 \%)$. While the differences between the positive and the negative frames and between the personal and situational frames do not achieve conventional levels of statistical significance, the directions of these differentials are consistent with the hypotheses that negative and personal frames will generate larger bandwagon effects than their positive and situational counterparts. Figures 1 and 2 provide additional data on how individuals evaluate candidates that support these findings of affective and attributional framing effects.

Figure 1 shows that subjects in the control group evaluated Florio an average of 7.6 points higher than Corzine in rating how warmly or coolly they felt toward each on 0-100 point feeling thermometer questions. ${ }^{3}$ Subjects presented with the information Corzine was likely to win rated him at a similar deficit to Florio of 7.0. However, when this same information is framed negatively, as a Florio loss, the gap narrows to 3.9 percentage points, a gain for Corzine.

Figure 2, derived from the attributional framing variation, shows a similar narrowing of the feeling thermometer gap across the different conditions. Relative to the control condition, the situational framing of expectations leads to a decrease in the feeling thermometer gap of .3 points (from a 7.6 percentage point gap in the control condition to a 7.3 percentage point gap in the situational condition). The personal framing condition produces much larger effect, narrowing the feeling thermometer gap to 3.6 percentage points. Despite the fact that these differences do not achieve conventional levels of statistical significance, the pattern of effects in candidate evaluations is generally supportive of the affective and attributional framing hypotheses.

Turning now to the question of how affective and attributional frames interact, Table 4 presents results that show the combinations of some frames 
Table 3. Difference in Voting for Expected Winner for Affective Expectations Frames and Attributional Expectations Frames

\begin{tabular}{|c|c|c|c|c|}
\hline & \multicolumn{4}{|c|}{ Affective Frames } \\
\hline & $\begin{array}{l}\text { No Expectations } \\
\text { Information } \\
\text { [Control Group 5] } \\
\quad \mathrm{n}=58\end{array}$ & \multicolumn{2}{|c|}{$\begin{array}{c}\text { Positive } \\
\text { Expectations Frame } \\
\text { [Experimental } \\
\text { Groups 1,2] } \\
\mathrm{n}=118\end{array}$} & $\begin{array}{c}\text { Negative } \\
\text { Expectations Frame } \\
\text { [Experimental } \\
\text { Groups } 3,4] \\
n=114\end{array}$ \\
\hline \multirow[t]{4}{*}{$\begin{array}{l}\text { Proportion } \\
\text { Voting for } \\
\text { Expected Winner }\end{array}$} & .24 & .37 & & .45 \\
\hline & $\begin{array}{l}\text { Mean Difference Po } \\
\text { Mean Difference Ne } \\
\text { Mean Difference Po }\end{array}$ & $\begin{array}{l}\text { e - Control } \\
\text { ve - Control } \\
\text { e - Negative }\end{array}$ & \multicolumn{2}{|c|}{$\begin{array}{l}=.13(.072)^{* *} \\
=.21(.073)^{* * *} \\
=.08(.065)\end{array}$} \\
\hline & \multicolumn{4}{|c|}{ Attributional Frames } \\
\hline & $\begin{array}{l}\text { No Expectations } \\
\text { Information } \\
\text { [Control Group 5] } \\
\quad \mathrm{n}=58\end{array}$ & \multicolumn{2}{|c|}{$\begin{array}{c}\text { Situational } \\
\text { Expectations Frame } \\
\text { [Experimental } \\
\text { Groups } 2,4] \\
\mathrm{n}=118\end{array}$} & $\begin{array}{c}\text { Personal } \\
\text { Expectations Frame } \\
\text { [Experimental } \\
\text { Groups } 1,2] \\
n=114\end{array}$ \\
\hline \multicolumn{5}{|l|}{$\begin{array}{l}\text { Proportion } \\
\text { Voting for } \\
\text { Expected Winner }\end{array}$} \\
\hline $\begin{array}{l}M \\
M \\
M\end{array}$ & \multicolumn{2}{|c|}{$\begin{array}{l}\text { Mean Difference Situational - Control } \\
\text { Mean Difference Personal - Control } \\
\text { Mean Difference Situational - Personal }\end{array}$} & \multicolumn{2}{|c|}{$\begin{array}{l}=.12(.072)^{* *} \\
=.22(.074)^{* * *} \\
=.10(.064)^{*}\end{array}$} \\
\hline$* \mathrm{p}<.10$ (one tailed); & $; * * \mathrm{p}<.05$ (one tailed) $; *$ & $<.01$ (one tailed) & & \\
\hline
\end{tabular}

produce more powerful effects than others. Consistent with the hypothesized effects, the data in the upper half of Table 4 show that the bandwagon effect on candidate vote choice is strongest in the negative-personal condition. The proportion of subjects voting for the expected winner in this condition is much larger than the proportion voting for the expected winner in the control condition, and this mean difference of .32 is statistically significant $(p<.001$, one-tailed test). While the bandwagon effects are not inconsequential for the other three conditions $(.13, .14$, and .11), the negative-personal 
Figure 1. Difference in Candidate Evaluations by Affective Expectations Frames

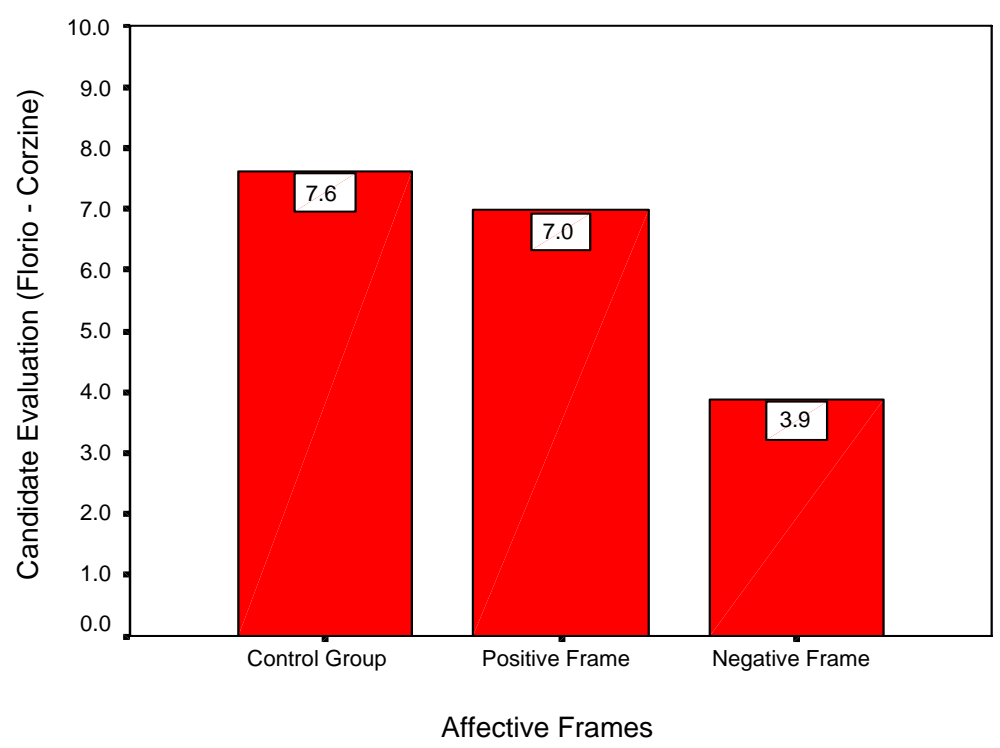

Figure 2. Difference in Candidate Evaluations by Attributional Expectations Frames

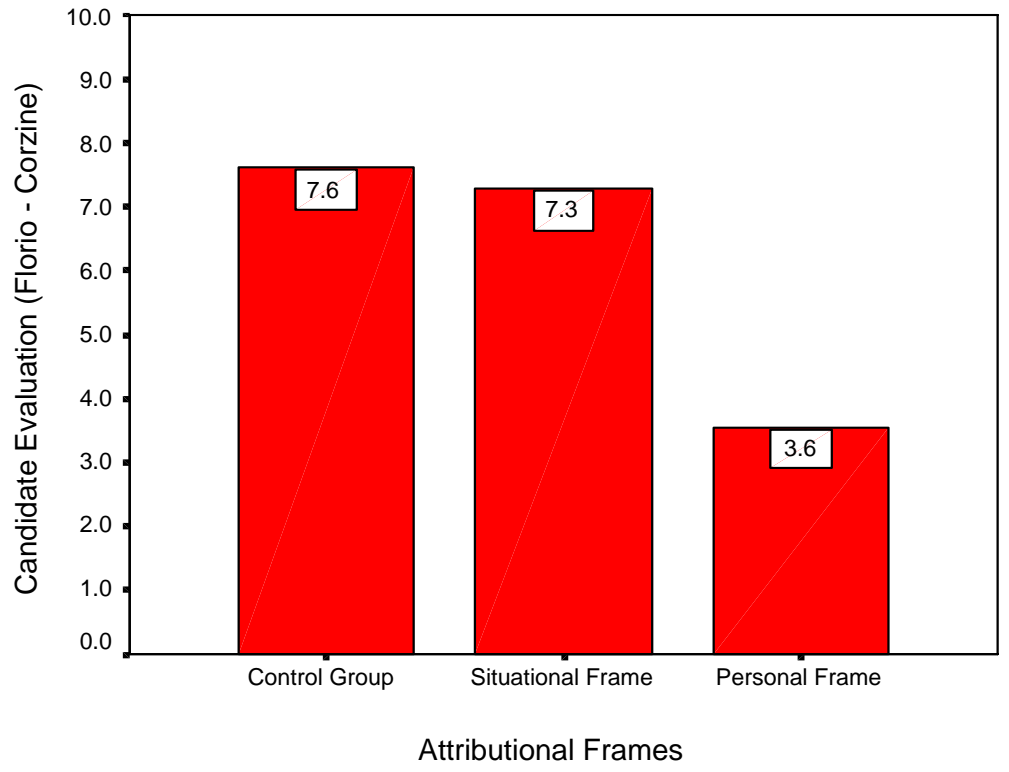


Table 4. Difference in Voting for Expected Winner by Affective and Attributional Expectations Frames

\begin{tabular}{lcc}
\hline Frame Type & $\begin{array}{c}\text { Proportion Voting for } \\
\text { Expected Winner }\end{array}$ & $\begin{array}{c}\text { Difference from Control } \\
\text { Group Mean (s.e.) }\end{array}$ \\
$\begin{array}{l}\text { Positive Personal } \\
\mathrm{n}=60\end{array}$ & .37 & $.13^{*}$ \\
Positive Situational \\
$\mathrm{n}=58$
\end{tabular}

frame is the only one in which knowledge that Corzine was the expected winner turned him into the preferred candidate for most subjects. Negatively-personally framed expectations transformed a 3 to 1 loser in the control condition into a majority winner. 
The analysis in the lower half of Table 4 shows that these framing effects are truly interactive. Looking only at the subjects exposed to situational frames, the affective nature of the expectations information they receive makes no real difference in their vote choice (.38 versus .35 propensity to vote for the expected winner). Negativity makes a difference only among those who receive a personal frame. Similarly, the personal-situational distinction makes no real difference among subjects in the positive framing condition (.37 versus .38). However, for negatively framed groups, exposure to a personal frame is statistically significant $(.21, \mathrm{p}<.05)$. Indeed, it seems that the combination of negative affect and personal attribution in the expectations frame is the driving force behind the bandwagon effects seen here.

\section{Conclusions}

The bandwagon effects observed in this particular context do appear to be fairly robust, especially in light of the relatively subtle framing manipulation used in the experiment. However, no experiment can demonstrate how all of the potentially relevant features of the expectations environment contribute to the development of bandwagons and to the nature of their effects. In addition, there are limits to the external validity of any experimental demonstration of effects such as these. The subject pool was composed entirely of college students, so it is unclear whether the observed framing effects would be present for the broader population. Finally, the experiment involved a highly specific manipulation of electoral expectations, in this case attributing electoral success or failure to personal or situational explanations for fundraising prowess.

Despite these limitations, several conclusions still hold regarding how affective and attributional frames influence the relationship between electoral expectations and vote choice. First, these findings support the claim that variations in the presentation of electoral expectations matter. Expectations framed in certain ways seem to affect vote choice more powerfully, while those framed in other ways have less substantial effects on such choices.

Second, the observed differences in the effects of expectations frames provide a fresh perspective on how the media can and should interpret expected electoral outcomes. The research presented here raises the prospect that certain expectations frames used by the media may be relatively harmless in that they provide information about likely election outcomes without significantly enhancing the likelihood of voting for the expected winner. The current problem in the media's coverage of the campaign as horserace may 
not have to do with whether they report on electoral expectations but with how they report on electoral expectations.

Third, while this research provides another example of the power of framing, it also suggests that citizens may react to certain frames in fairly sensible ways. For example, citizens do not evaluate all expected losers in the same way. They most severely punish (by voting against them) those who are losing due to personal factors, and they hold those who are losing due to situational circumstances less responsible. Here the glass may be only half full, since individuals do not seem to make a similar distinction between the causal explanations offered for why candidates are expected to win. However, it is encouraging that citizens see this distinction and respond to it in some circumstances.

Because horserace information is ubiquitous and bandwagon effects are well established, it is important to understand people's tendency to support the winner. Beyond confirming the idea that exposure to expectations information creates significant bandwagon effects, the results presented here advance our understanding of this phenomenon by revealing some ways that the framing of electoral expectations influences citizen voting decisions. Their substantive importance for understanding how particular expectations frames affect vote choice aside, these findings indicate more generally that the relationship between electoral expectations and candidate evaluations may be more complex than first assumed. Importantly, they suggest that our understanding of bandwagon effects needs to include not only the idea that people tend to support expected winners, but also that the degree to which they do so depends on why they expect them to win.

\section{APPENDIX \\ Text of the Experimental Manipulation}

Group 1 (Positive-Personal)

"Corzine has worked tirelessly to raise the money he needs to win, and it is that hard work that should make the difference on election day."

Group 2 (Positive-Situational)

"Corzine is fortunate to be in a situation in which he has the money he needs to win, and it is this state of affairs that should make the difference on election day."

Group 3 (Negative-Personal)

"Florio hasn't has worked enough to raise the money he needs to win, and it is that lack of effort that should make the difference on election day." 
APPENDIX (continued)

Group 4 (Negative-Situational)

"Florio is unfortunate to be in a situation in which he doesn't have the money he needs to win, and it is this state of affairs that should make the difference on election day."

Group 5 (Control)

Received no information regarding who was expected to win the race.

\section{NOTES}

${ }^{1}$ Vote choice was operationalized by asking subjects, "In the election you just read about which candidate would you vote for," and offering a forced choice alternative between Jon Corzine and Jim Florio.

${ }^{2}$ The threat to experimental validity that subjects had outside knowledge of the inaccuracies in the account of the race were minimal since the experiment was done in Massachusetts, but it used a Senate primary race contested in New Jersey. In the post-test questionnaire, subjects were asked if they had any prior knowledge regarding the Corzine/Florio race before beginning the experiment, and 90.6 percent reported they had not heard anything about the race. Only 3.8 percent of the subjects claimed they could remember any specific information they had heard about the race.

${ }^{3}$ I focus on differences in feeling thermometer ratings rather than absolute ratings of the expected winner both because these feeling thermometer questions are presented one after another in the post-test questionnaire and because subjects learn about these candidates in an electoral context that implies a choice between the two.

\section{REFERENCES}

Ansolabehere, Stephen, and Shanto Iyengar. 1995. Going Negative: How Political Advertisements Shrink and Polarize the Electorate. New York: Free Press.

Bartels, Larry. 1985. Expectations and Preferences in Presidential Nominating Campaigns. American Political Science Review 79:804-815.

Birnbaum, Michael H. 1972. Morality Judgments: Tests of an Averaging Model. Journal of Experimental Psychology 93:35-42.

Brady, Henry E., and Richard Johnston. 1987. What's the Primary Message: Horserace or Issue Journalism? In Gary Orren and Nelson Polsby, eds. Media and Momentum: The New Hampshire Primary and Nomination Politics. Chatham, NJ: Chatham House.

Cacioppo, John T., and Gary G. Berntson. 1994. Relationship between Attitudes and Evaluative Space: A Critical Review, with Emphasis on the Separability of Positive and Negative Substrates. Psychological Bulletin 115:401-423. 
Cacioppo, John T., Wendi L. Gardner, and Gary G. Berntson. 1997. Beyond Bipolar Conceptualizations and Measures: The Case of Attitudes and Evaluative Space. Personality and Social Psychology Review 1:3-25.

Finkel, Steven, and John Geer. 1998. A Spot Check: Casting Doubt on the Demobilizing Effect of Attack Advertising. American Journal of Political Science 42:573-595.

Fiske, Susan T. 1980. Attention and Weight in Person Perception: The Impact of Negative and Extreme Information. Journal of Experimental Psychology: Learning Memory, and Cognition 38:889-906.

Fiske, Susan T., and Shelley E. Taylor. 1991. Social Cognition. New York: McGrawHill.

Forgas, Joseph P. 1998. On Being Happy and Mistaken: Mood Effects on the Fundamental Attribution Error. Journal of Personality and Social Psychology 75:318-331.

Freedman, Paul, and Ken Goldstein. 1999. Measuring Media Exposure and the Effects of Negative Campaign Ads. American Journal of Political Science 43:1189-1208.

Freedman, Paul. 1996. Framing the Partial Birth Abortion Debate: A Survey Experiment. Paper presented at the Annual Meeting of the Midwest Political Science Association, Chicago.

Gilbert, Daniel T., and Patrick S. Malone. 1995. The Correspondence Bias. Psychological Bulletin. 117:21-38.

Gross, Kimberly. 2000. The Limits of Framing: How Framing Effects May Be Limited or Enhanced by Individual Level Predispositions. Paper presented at the Annual Meeting of the Midwest Political Science Association, Chicago.

Hamilton, David L., and Mark P. Zanna. 1974. Context Effects in Impression Formation: Changes in Connotative Meaning. Journal of Personality and Social Psychology 29:649-654.

Heider, Fritz. 1958. The Psychology of Interpersonal Relations. New York: Wiley.

Ito, Tiffany A., Jeff T. Larsen, N. Kyle Smith, and John T Cacioppo. 1998. Negative Information Weighs More Heavily on the Brain: The Negativity Bias in Evaluative Categorizations. Journal of Personality and Social Psychology 75:887-900.

Jones, Edward E. 1979. The Rocky Road from Acts to Dispositions. American Psychologist 34:107-117.

Jones, Edward E., and Victor A. Harris. 1967. The Attribution of Attitudes. Journal of Experimental Social Psychology 3:1-24.

Just, Marion R., Ann N. Crigler, Dean E. Alger, Timothy E. Cook, Montague Kern, and Darrell M. West. 1996. Crosstalk: Citizens, Candidates, and the Media in a Presidential Campaign. Chicago: University of Chicago Press.

Kahn, Kim Fridkin, and Patrick J. Kenney. 1999. Do Negative Campaigns Mobilize or Suppress Turnout? Clarifying the Relationship between Negativity and Participation. American Political Science Review 93:877-889.

Kelley, Harold H. 1972. Attribution and Social Interaction. In Attributions: Perceiving the Causes of Behavior, ed. Edward E. Jones. Morristown, NJ: General Learning Press.

Kenney, Patrick J., and Tom W. Rice. 1994. The Psychology of Political Momentum. Political Research Quarterly 47:923-939.

Kinder, Donald, and Lynn Sanders. 1990. Mimicking Political Debate with Survey Questions: The Case of White Opinion on Affirmative Action for Blacks. Social Cognition 8:73-103. 
Lau, Richard. 1982. Negativity in Person Perception. Political Behavior 4:353-377.

Lau, Richard. 1985. Two Explanations for Negativity Effects in Political Behavior. American Journal of Political Science 29:119-138.

Lavrakas, Paul J., Jack K. Holley, and Peter V. Miller. 1991. Public Reactions to Polling News During the 1988 Presidential Campaign. In Paul J. Lavrakas and Jack K. Holley, eds. Polling and Presidential Election Coverage. Newbury Park, CA: SAGE Publications.

Mayer, Russell K. 2001. What to Expect from Media Expectations. Harvard International Journal of Press and Politics 6:71-89.

McGraw, Kathleen M., and Marco Steenbergen. 1997. Pictures in the Head: Memory Representation of Political Candidates. In Milton Lodge and Kathleen M. McGraw, eds. Political Judgment: Structure and Process. Ann Arbor: University of Michigan Press.

McKelvey, Richard D., and Peter C. Ordeshook. 1985. Elections with Limited Information: A Fulfilled Expectations Model Using Contemporaneous Poll and Endorsement Data as Information Sources. Journal of Economic Theory 36:55-86.

Mehrabian, Albert. 1998. Effects of Poll Reports on Voter Preferences. Journal of Applied Social Psychology 28:2119-2130.

Morin, Richard. 1995. The 1992 Election and the Polls: Neither Politics nor Polling as Usual. In Paul J. Lavrakas, Michael W. Traugott, and Peter V. Miller, eds. Presidential Polls and the News Media. Boulder: Westview Press.

Mutz, Diana C. 1997. Mechanisms and Momentum: Does Thinking Make It So? Journal of Politics 59:104-126.

Nelson, Thomas, Zoe Oxley, and Rosalee Clawson. 1997. Media Framing of a Civil Liberties Conflict and Its Effect on Tolerance. American Political Science Review 91:567-583.

Norenzayan, Ara, and Richard E. Nisbett. 2000. Culture and Causal Cognition. Current Directions in Psychological Science 9:132-135.

Patterson, Thomas. 1980. The Mass Media Election: How Americans Choose Their President. New York: Praeger.

Quattrone, George A. 1982. Overattribution and Unit Formation: When Behavior Engulfs the Person. Journal of Personality and Social Psychology 42:593-607.

Ross, Lee. 1977. The Intuitive Psychologist and His Shortcomings: Distortions in the Attribution Process. In Leonard Berkowitz, ed. Advances in Experimental Social Psychology. San Diego: Academic Press.

Smith, Peter B., and Michael H. Bond. 1994. Social Psychology Across Cultures: Analysis and Perspective. Needham Heights, MA: Allyn and Bacon.

Taylor, Shelley E., and Susan T. Fiske. 1975. Point of View and Perception of Causality. Journal of Personality and Social Psychology 32:439-445.

Traugott, Michael W. 1992. The Impact of Media Polls on the Public. In Thomas E. Mann and Gary R. Orren, eds. Media Polls in American Politics. Washington, DC: The Brookings Institution.

Zaller, John. 1990. The Nature and Origin of Mass Opinion. Cambridge: Cambridge University Press. 